\title{
N200, N250r, and N400 Event-Related Brain Potentials Reveal Three Loci of Repetition Priming for Familiar Names
}

\author{
Esther C. Pickering and Stefan R. Schweinberger \\ University of Glasgow
}

\begin{abstract}
The authors assessed immediate repetition effects on event-related potentials (ERPs) while participants performed familiarity decisions for written personal names. For immediately repeated familiar names, the authors observed 3 distinct ERP modulations. At $180-220 \mathrm{~ms}$, a posterior N200 effect occurred for names preceded by same-font primes only. In addition, an increased left temporal negativity (N250r, 220-300 ms) and a reduced central-parietal negativity (N400, 300-400 ms) were seen both for same-font and different-font repetitions. In a 2nd experiment, when names were preceded by either their corresponding face or the face of a different celebrity, only the N400 effect was preserved. These findings suggest that the N200, N250r, and N400 effects reflect facilitated processing at font-specific featural, lexical, and semantic levels of processing, respectively.
\end{abstract}

Priming can be described as a facilitation in stimulus processing that is induced by prior exposure to an identical or highly related stimulus. Priming paradigms have been used to explore cognitive operations engaged during the processing of commonly encountered stimuli such as words (e.g., Morton, 1969, 1979), pictures of objects (e.g., Schacter, Delaney, \& Merikle, 1990), faces (e.g., Bruce \& Valentine, 1985), and personal names (e.g., Calder \& Young, 1996; Young, Hellawell, \& DeHaan, 1988).

Although processing is typically enhanced for repeated items, priming may facilitate processing at various levels, and responses to primed stimuli are mediated by a range of factors (Tenpenny, 1995). Response time (RT) measures show that at short intervals between prime and target, priming benefits can cross stimulus modalities. ${ }^{1}$ For example, participants are faster to perform a familiarity decision task when the faces of familiar persons are preceded by their names. Priming benefits gained from exposure to cross-modal or semantically related stimuli are usually short-lived, are attributed to semantic rather than perceptual processing, and are reduced or eliminated when prime-to-target lags exceed more than a few seconds (except in special circumstances; see, e.g., Burton, Kelly, \& Bruce, 1998). However, greater and longer lasting increases in facilitation are observed when the same item is encountered on first and second presentation, and priming benefits are further increased if the task performed on both occasions is identical (e.g., Ellis, Flude, Young, \& Burton, 1996; but, see also Ellis, Young, \& Flude, 1990, for qualifications). Repetition prim-

Esther C. Pickering and Stefan R. Schweinberger, Department of Psychology, University of Glasgow, Glasgow, Scotland, United Kingdom.

This research was supported by a research grant from the Royal Society (United Kingdom) to Stefan R. Schweinberger and by a faculty postgraduate studentship to Esther C. Pickering. Many thanks go to Jürgen Kaufmann for help in setting up the experiment, to Ines Jentzsch for help in data collection, and to Patrick Berg for software support.

Correspondence concerning this article should be addressed to Stefan R. Schweinberger, Department of Psychology, University of Glasgow, 58 Hillhead Street, Glasgow, Scotland G12 8QQ, United Kingdom. E-mail: s.schweinberger@psy.gla.ac.uk ing for stimuli such as faces is resistant to certain perceptual manipulations such as changes to image size and position (Brooks, Rosielle, \& Cooper, 2002; Bruce \& Young, 1986). Priming for meaningless letter strings can be long lasting under certain conditions (Stark \& McClelland, 2000). However, priming may facilitate multiple levels of processing, and priming differences between familiar and novel items have been demonstrated in lexical decision tasks. For example, Bentin and Moscovitch (1988) found equivalent RT facilitation for words and nonwords when primed by immediate repetition. In contrast, when a number of trials intervened between repetitions, priming effects disappeared for nonwords, whereas they persisted for words.

Morton $(1969,1979)$ explained word priming in terms of the modification of abstract word recognition units (RUs) called logogens. Logogens are conceptualized as threshold devices, where a threshold of activation must be exceeded before the logogen fires. Repetition of a word is thought to either lower the threshold of its logogen or increase its level of activation above baseline. In consequence, a repeated word will be recognized faster. In contrast, interactive activation and competition (IAC) models of person recognition hold that this type of change in activation levels of RUs would only support transient priming over short prime-target intervals. These models suggest that repetition priming over longer intervals can be explained by a modification of links within structural representations for persons (Bruce \& Young, 1986; Burton, Bruce, \& Johnston, 1990; also cf. Burton, Bruce, \& Hancock, 1999; Vitkovitch \& Humphreys, 1991; Wheeldon \& Monsell, 1992). According to this approach, repeated viewing of the photograph of a person's face gives rise to a long-lasting reinforcement of connections between modality-specific face recognition units (FRUs) and modality-independent person identity nodes (PINs). The short-lived nature of cross-modality priming is ex-

\footnotetext{
${ }^{1}$ Throughout this article, the words mode, modal, and modality refer to distinctions between stimulus types or domains rather than sensory modalities. For example, pictorial and orthographic stimuli have qualitatively different visual properties, although both are subject to visual perceptual processes.
} 
plained in terms of a transient priming effect centered on the PIN, to which face, name, voice, and all other modality-specific RUs are connected. However, immediate repetition priming is supported by multiple processes, centered on short-lived RU and PIN activation effects and long-lived strengthening of links from the RU to the PIN.

Supporting this account, some studies have shown equivalent priming for words across large manipulations in visual form (Clarke \& Morton, 1983; Feustel, Shiffrin, \& Salasoo, 1983; Morton, 1979). However, several studies report compelling evidence for additional, perceptually specific, word priming effects, as reflected in reduced priming when prime and target words were presented in a different case or a different font (e.g., Burgund \& Marsolek, 1997; Jacoby \& Hayman, 1987; Marsolek, Kosslyn, \& Squire, 1992). These findings may be reconciled by considering the possibility that different mechanisms mediate priming for different types of material. For example, Bowers (1996) presented target words and pseudowords (in lowercase) that had been primed either by uppercase or lowercase versions. He found that repetition priming for words was largely insensitive to these changes in visual form. For pseudowords, however, priming was much weaker for large compared with small changes in presentation. Large changes were defined by stimuli containing letters that share few visual features between their upper- and lowercase versions (e.g., $A, a ; G, g ; R, r$ ), whereas small changes were defined by stimuli containing letters that share many features between their upper- and lowercase versions (e.g., $C, c ; P, p ; S, s)$. Bowers proposed that the word priming effects were due to the modification of case-independent representations for words (analogous to RUs described above), whereas a separate form-specific featural system appeared to be involved in pseudoword priming.

Further evidence suggests that abstract and form-specific information about words may be processed in neuroanatomically separate systems. For instance, Marsolek et al. (1992) found larger same-case priming than different-case priming for target words preceded by primes that had been presented to the right hemisphere. The same advantage was absent when primes had been presented to the left hemisphere. Consistent findings were subsequently reported for pseudowords (Burgund \& Marsolek, 1997), letterlike forms (Marsolek, 1995), and pictures of objects (Marsolek, 1999). It would therefore appear that both early formspecific mechanisms and those mechanisms that facilitate access to abstract representations of words contribute to behaviorally observable priming. Some evidence suggests that form-specific priming processes are localized to the right hemisphere (for further evidence, see Doyle, Rugg, \& Wells, 1996; Koutstaal et al., 2001; but, see also Kroll, Rocha, Yonelinas, Baynes, \& Frederick, 2001, for negative findings), although word recognition is more efficiently mediated by the left hemisphere.

Personal names are a class of words that has attracted much scientific interest because the processing of names may differ from other types of words in several interesting ways. Personal names are notoriously difficult to learn and retrieve, relative to both common names (Brédart, 1993) and other person-specific biographical facts (Abdel Rahman, Sommer, \& Schweinberger, 2002). Although clearly lexical items, personal names differ from common names in having a unique referent. Cognitive models of name recognition (Valentine, Brédart, Lawson, \& Ward, 1991) have borrowed many theoretical concepts from models of face recognition (Bruce \& Young, 1986). Personal names can exhibit selective sparings and deficits after brain damage, suggesting that their neural representation differs from that for common names (Brédart, Brennen, \& Valentine, 1997; Neuner \& Schweinberger, 2000; Semenza, Mondini, \& Zettin, 1995; VanLancker \& Klein, 1990). Personal names can also show a different pattern of priming phenomena than that shown by common words (Hollis \& Valentine, 2001; Valentine, Hollis, \& Moore, 1998). These findings for personal names have been attributed to the idea that names are unique, meaningless labels (Burton \& Bruce, 1992; Cohen, 1990), that they are specific labels referring to a subordinate level of a conceptual hierarchy (Tranel, Damasio, \& Damasio, 1997), or that many names are similar to pseudowords in that they are rarely encountered and their phonology is difficult to specify (Brennen, 1993).

In the experiments discussed in the present article, we used event-related brain potentials (ERPs) to further explore priming processes in the recognition of written names. ERPs consist of transient voltage changes in the electroencephalogram (EEG) that are time-locked to certain events such as the onset of a particular stimulus. ERPs provide a millisecond-by-millisecond window to the neural processes that are modulated by priming, and therefore they have been widely used to chronometrically delineate processing stages involved in priming and recognition (Bentin \& McCarthy, 1994; Dehaene et al., 2001; Joyce, Paller, Schwartz, \& Kutas, 1999; Paller \& Gross, 1998; Rugg, 1987; Rugg, Doyle, \& Wells, 1995; Schweinberger, 2001; Tsivilis, Otten, \& Rugg, 2001). The N400 is probably the best-known ERP that is sensitive to priming. This is a negative component maximal around $400 \mathrm{~ms}$ after stimulus onset (Kutas \& Hillyard, 1980) that was initially observed for terminal words of sentences that violate the semantic context (e.g., "I drink my coffee with milk and socks"). The N400 is attenuated both by repetition priming and semantic priming (Bentin, McCarthy, \& Wood, 1985; Rugg, 1987). Thus, the N400 amplitude appears to be a function of the difficulty with which an item can be integrated with its semantic context.

Compared with semantic priming, there is evidence that repetition priming not only elicits a much larger reduction in N400 amplitude but also modulates earlier and qualitatively different ERP components. For instance, in studies investigating repetitions across long intervals and many intervening items, Rugg (1987) reported a nonsignificant early increase in negativity around 200 $\mathrm{ms}$ for repeated words over midline and left temporal electrodes, and Schweinberger (2001) reported a significant increase in negativity around $200 \mathrm{~ms}$ at temporal areas for repeated voices. Using repetitions across shorter intervals, researchers consistently found an increased negativity at right inferior temporal electrodes with a latency of approximately 200-300 ms, termed $N 250 r$, for repeated items in studies of familiar face priming (Begleiter, Porjesz, \& Wang, 1995; Pfütze, Sommer, \& Schweinberger, 2002; Schweinberger, Pfütze, \& Sommer, 1995; Schweinberger, Pickering, Jentzsch, Burton, \& Kaufmann, 2002).

There are a number of reasons why personal names are particularly well suited as verbal stimuli to compare with faces. Although both names and faces refer to unique persons, there is evidence from ERPs for a strong left hemisphere involvement in name recognition (Dehaene, 1995; Proverbio, Lilli, Semenza, \& Zani, 2001), which contrasts with the evidence for right hemisphere involvement in face recognition. In line with these results, 
the N250r repetition effect was recently found to be maximal at right hemisphere temporal sites for faces but at left hemisphere areas for names. Moreover, the N250r appears to be sensitive to stimulus familiarity, as it was smaller in amplitude for unfamiliar repeated names and faces (compared with counterpart familiar stimuli; Pfütze et al., 2002). Schweinberger and his colleagues therefore proposed that the N250r component reflects modalityspecific recognition processes, presumably at the level of RUs (for a recent overview, see Schweinberger \& Burton, 2003). However, differences in N250r amplitude have been found between conditions of different-photograph priming (i.e., Photo B prime-Photo A target) and same-photograph priming (i.e., Photo A prime-Photo A target) (Schweinberger, Pickering, Jentzsch, et al., 2002). As a consequence, the extent to which the N250r is modulated by form-specific featural processing deserves further investigation. In the experiments described in the present article we used a manipulation of font to investigate this issue.

It is worth noting that the N250r elicited by short-term repetition priming is absent when longer time intervals (i.e., more than 15 min) and several hundred stimuli intervened between any repetitions (Schweinberger, Pickering, Burton, \& Kaufmann, 2002). At a functional level, it has been argued that changes at the level of RUs are too transient in nature to explain long-term repetition priming (e.g., Bruce, Carson, Burton, \& Kelly, 1998). Instead, long-term priming may involve a strengthening of the connections of perceptual nodes to postperceptual memory nodes (specifically, links from RUs to PINs; Burton et al., 1990). The idea that long-term priming involves a change in the links between representations - rather than a change in activation levels of the representations themselves-is also widespread in word and object recognition research (Vitkovitch \& Humphreys, 1991; Wheeldon \& Monsell, 1992). In contrast, increased activation levels, or decreased thresholds, at the level of RUs may significantly contribute to short-term or immediate repetition priming (Bruce \& Valentine, 1985; Morton, 1979).

In Experiment 1, we explored ERP effects of immediate repetition priming for familiar personal names. On the basis of previous evidence (Pfütze et al., 2002; Schweinberger et al., 1995), we expected at least two different ERP modulations: First, we expected a reduced centro-parietal N400 component to be seen for repeated names. Second, we expected an increased N250r component, particularly over left temporal electrode sites. In addition, we included both same-font and different-font repetitions in this experiment. We hoped to be able to distinguish between ERP differences related to form-specific featural priming (related to samefont name repetitions) and repetition priming (related to both same- and different-font name repetitions).

\section{Experiment 1}

\section{Method}

Participants. Twelve participants ( 7 women and 5 men) aged between 18 and 42 years $(M=23.3$ years) were paid ( $£ 5$ per hour [approximately U.S.\$7.50 per hour]) to contribute data to this study. All participants were right-handed, as indicated by an adapted version of the Edinburgh Handedness Questionnaire (Oldfield, 1971; $M=+95.8$ ). All participants reported normal or corrected-to-normal visual acuity.

Stimuli and apparatus. Names of 90 famous people from various areas (e.g., politics, entertainment, sports, television) were used as targets in the present experiment. The celebrities were selected from a list of more than 600 celebrities on the basis of highest ratings for ease of name recognition in a preliminary study, scoring an average of 1.96 out of 2 (means across 11 raters, scores on a 3-point scale from 0 [don't recognize] to 2 [definitely recognize]). Ninety unfamiliar names were also used as targets to create the task demands and were matched to famous counterparts with respect to gender, number of syllables, and cultural background. Two versions of each name were prepared that differed only with respect to the font in which the name was presented. The two fonts used were IBM-8bit and Bernard MT condensed. Bernard MT condensed font was used only for prime names in the primed-different condition (see Figure 1). Names were presented in capitals, forename above surname, in the center of the screen. Characters were $6 \mathrm{~mm}$ in height. The 90 famous names were further subdivided into three sets (with 30 names each). The assignment of name set to experimental condition (unprimed, primed same, or primed different; see below) was completely counterbalanced across participants

Procedure. Participants performed the experiment in an electrically shielded and sound-attenuated cabin. After the EEG electrodes were applied and prior to the experiment, participants received written task instructions. Before the experiment began, 6 trials were presented for demonstration, and a further 10 trials preceded critical trials for practice reasons; the names shown in these 16 trials were not shown subsequently.

Each trial consisted of the presentation of a prime name and a target name in succession. At the beginning of each trial, a white fixation cross appeared for $500 \mathrm{~ms}$ and was then replaced by a prime name, presented for $500 \mathrm{~ms}$ and followed by a green fixation circle for $1,300 \mathrm{~ms}^{2}$ This was replaced by a target name, presented for $1,500 \mathrm{~ms}$. Participants were told to decide by speeded two-choice keypresses whether the second name was famous or unfamiliar. Speed and accuracy were emphasized. Half of the participants responded with their right index finger to indicate a famous person and with their left index finger to indicate an unfamiliar person. For the other half of the participants, this assignment was reversed. Incorrect or missing responses were indicated by two $300-\mathrm{ms}$ feedback tones $(500 \mathrm{~Hz}$ and $650 \mathrm{~Hz}$, respectively).

A total of 180 critical trials were presented, with 90 familiar target names and 90 unfamiliar target names. One third of familiar target names were preceded by a different familiar name (unprimed condition). One third of familiar target names were preceded by the same name, presented in the same font (primed-same condition). One third of familiar target names were preceded by the same name but presented in a different font (primed-different condition). Figure 1 gives examples.

To prevent any predictive value of the prime with respect to the forthcoming response, the same prime stimuli that were used for familiar target names were used for the 90 unfamiliar target names as well. Moreover, all 180 trials of the block were shown in completely randomized order. Throughout the experiment, short breaks were allowed after every 60 critical trials. In an additional block of trials, participants performed blinks (20 trials) as well as horizontal and vertical eye movements of predefined visual angle (10 trials each). These served as an individual calibration for later correction of ocular contributions to the EEG (see below).

Performance. Responses were scored as correct if the correct key was pressed within a time window lasting from $200 \mathrm{~ms}$ to $1,500 \mathrm{~ms}$ after stimulus onset. Errors of omission (no keypress) and of commission (wrong keypress) were recorded separately. Mean RTs were calculated for correct responses only.

\footnotetext{
${ }^{2}$ This relatively long stimulus onset asynchrony (SOA) between prime and target avoided the complication of a temporal overlap between the ERPs elicited by the target and those elicited by the preceding prime. An SOA of $1,800 \mathrm{~ms}$ is similar to what is used by most ERP studies of immediate repetition priming, but it is clear that such a long interval allows for both automatic and strategic contributions to any priming effects observed.
} 


\section{Primed Same Primed Different Unprimed}

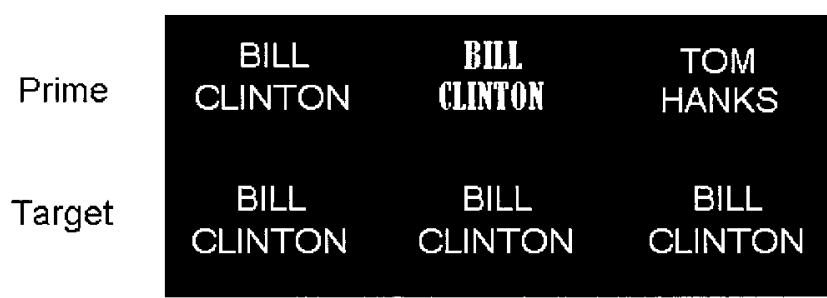

Figure 1. Examples of the prime and target names in Experiment 1. Bottom row shows target names and top row shows the prime names for the primed-same, primed-different, and unprimed conditions, respectively.

ERPs. The EEG was recorded with sintered $\mathrm{Ag} / \mathrm{AgCl}$ electrodes mounted in an electrode cap (Easy-Cap; FMS Falk Minow Services, Herrsching-Breitbrunn, Germany) at the scalp positions $\mathrm{F}_{\mathrm{Z}}, \mathrm{C}_{\mathrm{Z}}, \mathrm{P}_{\mathrm{Z}}, \mathrm{I}_{\mathrm{Z}}, \mathrm{Fp}_{1}$, $\mathrm{Fp}_{2}, \mathrm{~F}_{3}, \mathrm{~F}_{4}, \mathrm{C}_{3}, \mathrm{C}_{4}, \mathrm{P}_{3}, \mathrm{P}_{4}, \mathrm{O}_{1}, \mathrm{O}_{2}, \mathrm{~F}_{7}, \mathrm{~F}_{8}, \mathrm{~T}_{7}, \mathrm{~T}_{8}, \mathrm{P}_{7}, \mathrm{P}_{8}, \mathrm{FT}_{9}, \mathrm{FT}_{10}, \mathrm{P}_{9}, \mathrm{P}_{10}$, $\mathrm{PO}_{9}, \mathrm{PO}_{10}, \mathrm{C}_{3}{ }^{\prime}, \mathrm{C}_{4}{ }^{\prime}, \mathrm{F}_{9}{ }^{\prime}, \mathrm{F}_{10}{ }^{\prime}, \mathrm{TP}_{9}$, and $\mathrm{TP}_{10}$ (Pivik et al., 1993). The $\mathrm{C}_{3}{ }^{\prime}$ electrode was positioned $0.75 \mathrm{~cm}$ anterior to the midpoint of a straight line between $\mathrm{C}_{3}$ and $\mathrm{C}_{1}$, and the $\mathrm{C}_{4}{ }^{\prime}$ electrode was positioned $0.75 \mathrm{~cm}$ anterior to the midpoint of a straight line between $\mathrm{C}_{4}$ and $\mathrm{C}_{2}$. The $\mathrm{F}_{9}{ }^{\prime}$ electrode was positioned $2 \mathrm{~cm}$ anterior to $F_{9}$ at the outer canthus of the left eye, and the $\mathrm{F}_{10}$ ' electrode was positioned $2 \mathrm{~cm}$ anterior to $\mathrm{F}_{10}$ at the outer canthus of the right eye. The positions $\mathrm{TP}_{9}$ and $\mathrm{TP}_{10}$ refer to inferior temporal locations over the left and right mastoids, respectively. The $\mathrm{TP}_{10}$ electrode served as initial common reference, and a forehead electrode $\left(\mathrm{AF}_{\mathrm{Z}}\right)$ served as ground. Electrode impedances were kept below $10 \mathrm{k} \Omega$ and were typically below $5 \mathrm{k} \Omega$. The horizontal electrooculogram (EOG) was recorded from $\mathrm{F}_{9}{ }^{\prime}$ and $\mathrm{F}_{10}{ }^{\prime}$ at the outer canthi of both eyes, and the vertical EOG was monitored from an electrode above the right eye against an electrode below the right eye. All signals were recorded in direct current (DC) mode, with low-pass filters set to $40 \mathrm{~Hz}(-6 \mathrm{~dB}$ attenuation, $12 \mathrm{~dB} /$ octave $)$ and sampled at a rate of $250 \mathrm{~Hz}$.

Offline, epochs were generated, lasting $1,700 \mathrm{~ms}$ and starting $216 \mathrm{~ms}$ before stimulus onset. Automatic artifact detection software (written by Patrick Berg) was run for an initial sorting of trials, and all trials were then visually inspected for artifacts of ocular (e.g., blinks, saccades) and nonocular origin (e.g., channel blockings or drifts). Trials with nonocular artifacts, saccades, or incorrect behavioral responses were discarded. For all remaining trials, ocular blink contributions to the EEG were corrected (Elbert, Lutzenberger, Rockstroh, \& Birbaumer, 1985). ERPs were averaged separately for each channel and for each experimental condition. Each averaged ERP was low-pass filtered at $10 \mathrm{~Hz}$ with a zero phase shift digital filter and recalculated to average reference (Lehmann, 1987), excluding the vertical EOG channel.

\section{Results}

Performance. Mean error rates and RTs to familiar target names are shown in Table 1 . No omissions were observed. Table 1 shows that error rates were low $(M=6.1 \%)$.

Correct RTs and error rates to familiar names were submitted to analyses of variance (ANOVAs) with repeated measures on priming condition (unprimed vs. primed different vs. primed same). Where appropriate, we performed epsilon corrections for heterogeneity of covariances, using the Huynh-Feldt method (Huynh \& Feldt, 1976) throughout.

The ANOVA of the RTs revealed a significant effect of priming, $F(2,22)=41.7, p<.001$. Bonferroni-corrected paired contrasts revealed that relative to the unprimed condition, priming was significant both by the same font as the target name, $F(1,11)=$ $60.4, p<.001$, and by a different font than the target name, $F(1$, $11)=36.0, p<.001$. There was no significant difference in RTs between the primed-same and the primed-different conditions, $F(1,11)=3.6, p>.20$ (uncorrected $p=.08$ ).

The ANOVA of the error rates also revealed a significant effect of priming, $F(2,22)=6.1, p<.05$. Bonferroni-corrected paired contrasts revealed that relative to the unprimed condition, priming was significant by a name printed in a different font, $F(1,11)=$ $8.0, p=.05$ (uncorrected $p=.0164$ ), although a comparison with names primed in the same font just failed to reach significance, $F(1,11)=5.9, p=.10$ (uncorrected $p=.0335$ ). There was no difference in error rates between the primed-same and the primeddifferent conditions, $F(1,11)<1$.

ERPs. ERPs to target names were quantified by mean amplitude measures in the time segments $110-140 \mathrm{~ms}$ (occipital $\mathrm{P}_{1}$ ), 180-220 ms (occipitotemporal N200), 220-300 ms, 300-400 ms, 400-500 ms, 500-600 ms, and 600-700 ms. The first two segments were chosen to correspond with distinct peaks in the waveforms; the 100-ms segments that followed were arbitrarily chosen All amplitude measures were taken relative to a 200-ms baseline preceding the target stimulus.

For every time segment, ANOVAs were then performed analogous to those for the RT data, except for the inclusion of an additional repeated measurements factor electrode. To protect against Type I errors resulting from post hoc selection of electrodes for the quantification of effects, we initially performed analyses based on the data from all 32 scalp electrodes. One should note that because the average reference sets the mean activity across all electrodes to zero, any condition effects in these ANOVAs are meaningful only in interaction with electrode site. Therefore, any condition effect reported for these analyses below is in interaction with electrode site. If significant effects of priming showed up in these overall ANOVAs, additional analyses were performed on specific regions of interest (ROIs) to further locate these effects. These ROIs were (a) prefrontal/lateral frontal $\left(\mathrm{Fp}_{1}\right.$, $\left.\mathrm{Fp}_{2}, \mathrm{~F}_{7}, \mathrm{~F}_{8}, \mathrm{FT}_{9}, \mathrm{FT}_{10}, \mathrm{~F}_{9}{ }^{\prime}, \mathrm{F}_{10}{ }^{\prime}\right)$, (b) frontal-central $\left(\mathrm{F}_{\mathrm{Z}}, \mathrm{F}_{3}, \mathrm{~F}_{4}\right.$, $\left.\mathrm{C}_{3}{ }^{\prime}, \mathrm{C}_{4}{ }^{\prime}\right)$, (c) central-parietal $\left(\mathrm{C}_{\mathrm{Z}}, \mathrm{P}_{\mathrm{Z}}, \mathrm{C}_{3}, \mathrm{C}_{4}, \mathrm{P}_{3}, \mathrm{P}_{4}\right)$, (d) temporal $\left(\mathrm{T}_{7}, \mathrm{~T}_{8}, \mathrm{P}_{7}, \mathrm{P}_{8}, \mathrm{TP}_{9}, \mathrm{TP}_{10}, \mathrm{P}_{9}, \mathrm{P}_{10}\right)$, and (e) occipital $\left(\mathrm{I}_{\mathrm{Z}}, \mathrm{O}_{1}, \mathrm{O}_{2}\right.$, $\left.\mathrm{PO}_{9}, \mathrm{PO}_{10}\right)$.

Figure 2 shows the priming effects for famous names. For the 110-140-ms segment, no significant effects of priming were observed $(F<1.5)$. Effects of priming were first significant in the $180-220$-ms segment, $F(62,682)=2.9, p<.01$. Bonferronicorrected paired contrasts suggested that relative to the unprimed condition, there was no priming by names printed in different font,

Table 1

Mean Reaction Times (RTs, in ms) and Percentages of Errors (PEs) for Target Names in Experiment 1

\begin{tabular}{ccr} 
Target names and conditions & RT & PE \\
\hline Famous names & & \\
Unprimed & 761 & 10.5 \\
Primed different & 624 & 3.4 \\
Primed same & 603 & 4.5 \\
Unfamiliar names & 801 & 2.6 \\
\hline
\end{tabular}




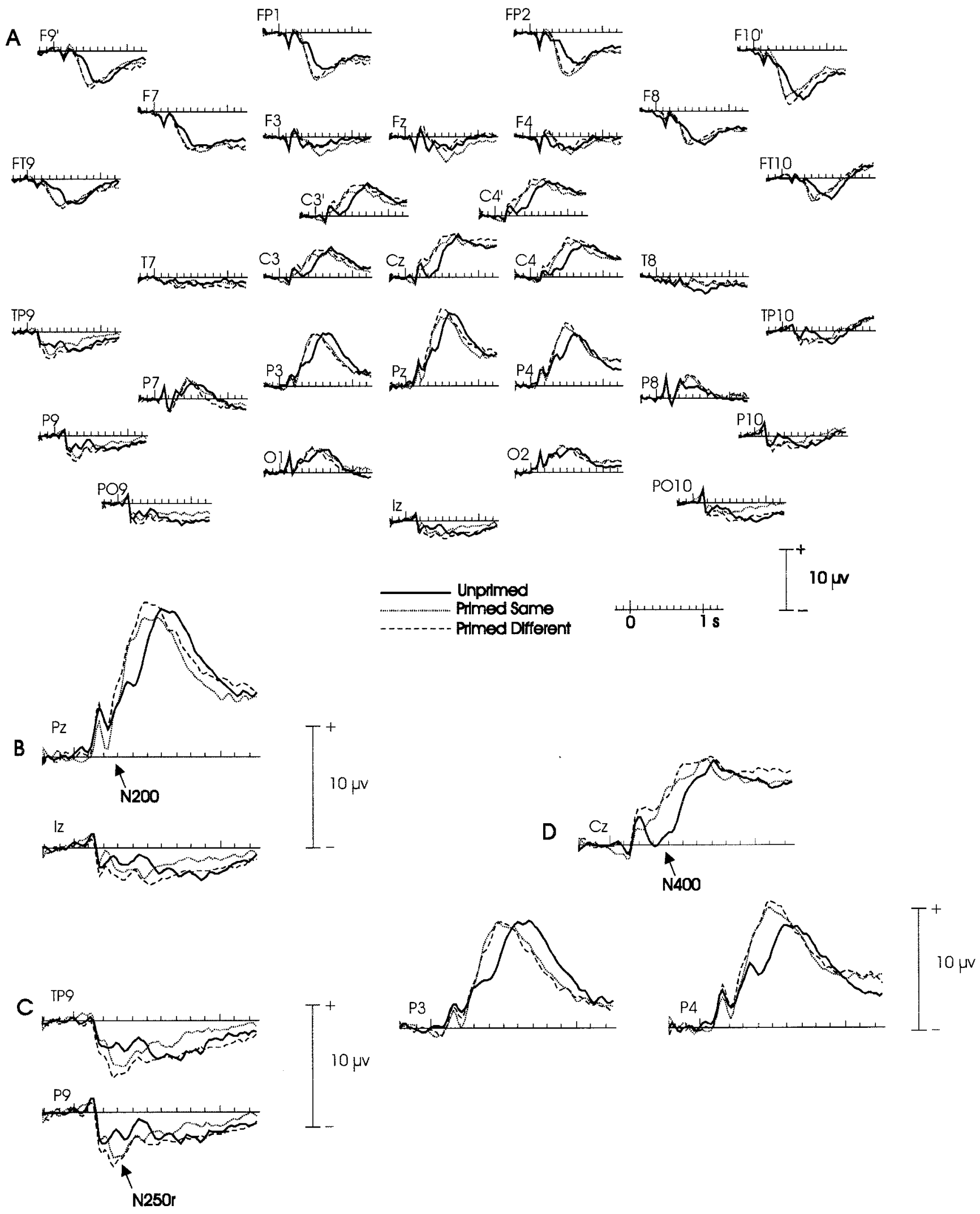

Figure 2. A: ERPs (event-related potentials) recorded for familiar target names that were unprimed and names that had been preceded by the same name either printed in same font or in a different font. Recordings are shown for all 32 electrode sites used. Panels B-D show ERPs for the same conditions as in Panel A but at selected electrode sites. B: ERPs at $P_{Z}$ and $I_{Z}$ illustrate the posterior font-specific effect in the time range at around $200 \mathrm{~ms}$. C: ERPs at TP and $\mathrm{P}_{9}$ show the left temporal $\mathrm{N} 250 \mathrm{r}$ for primed names. D: ERPs at $\mathrm{C}_{\mathrm{Z}}, \mathrm{P}_{3}$, and $\mathrm{P}_{4}$ show the $\mathrm{N} 400$ priming effect. 
$F(31,341)<1$. However, the difference between the primed-same and primed-different conditions was significant, $F(31,341)=4.6$, $p<.01$, and there was also evidence for priming by names printed in the same font, $F(31,341)=2.7, p=.09$ (uncorrected $p=.03$ ). Significant priming effects were seen at central-parietal, $F(2$, $22)=7.7, p<.01$; occipital, $F(2,22)=3.5, p<.05$; and temporal sites, $F(2,22)=5.9, p<.01$, but not at the other regions.

Significant effects of priming were also seen in the $220-300-\mathrm{ms}$ segment, $F(62,682)=4.7, p<.001$. Relative to the unprimed condition, priming was significant by the same font, $F(31,341)=$ $3.0, p<.05$, and by a different font, $F(31,341)=6.6, p<.001$. There was also a significant difference between the primed-same and primed-different conditions, $F(31,341)=3.7, p<.05$, apparently reflecting somewhat larger priming effects for the primed-different condition (for an explanation, see the topographic analyses below). The priming effects were particularly clear at temporal regions, $F(2,22)=13.1, p<.001$, but were also seen at other sites except prefrontal/lateral frontal sites $(F<1)$, frontalcentral, $F(2,22)=7.1, p<.01$; central-parietal, $F(2,22)=5.7$, $p<.05$; occipital, $F(2,22)=4.9, p<.05$.

Priming was significant in the 300-400-ms segment also, $F(62$, $682)=5.1, p<.001$. Relative to the unprimed condition, priming was significant both by the same, $F(31,341)=7.7, p<.001$, and by a different font, $F(31,341)=6.5, p<.001$. Moreover, the differences between the primed-same and primed-different conditions were no longer seen in the $300-400-\mathrm{ms}$ segment, $F(31$, $341)<1$. Priming effects were particularly clear at central-parietal regions, $F(2,22)=14.2, p<.001$, but were also seen at other regions except for occipital regions $(F<1)$, prefrontal/lateral frontal, $F(2,22)=5.4, p<.05$; frontal-central, $F(2,22)=6.7$, $p<.01$; temporal, $F(2,22)=6.4, p<.01$. Analysis of mean amplitudes in the 400-500-ms segment gave rise to a very similar picture, with a significant effect of priming, $F(62,682)=10.8$, $p<.001$. Priming was again significant by the same font, $F(31$, $341)=14.1, p<.001$, and by a different font, $F(31,341)=16.3$, $p<.001$, with no differences between the primed-same and primed-different conditions, $F(31,341)<1$. Priming effects were particularly clear at central-parietal regions, $F(2,22)=34.6, p<$ .001 , and at prefrontal/lateral frontal regions, $F(2,22)=31.9, p<$ .001 . No overall priming effects were seen at other regions (all ps $>.10) .^{3}$

Priming effects in the 500-600-ms segment were still significant, $F(62,682)=2.2, p<.05$, but none of the pairwise post hoc comparisons between priming conditions turned out to be significant. Moreover, priming effects were no longer significant in the $600-700$-ms segment, $F(62,682)=1.5, p>.10$.

Topographic analyses. Figure 2 suggests that we observed three qualitatively different priming effects between $180 \mathrm{~ms}$ and $400 \mathrm{~ms}$. This may be most obvious by considering the difference between the primed-same and unprimed conditions. Figure 4 illustrates this by presenting topographical maps of priming-related difference waves at three different latencies: (a) In the N200 segment (180-220 ms), priming elicited a posterior modulation with more negativity for names repeated in the same font only; (b) between $220 \mathrm{~ms}$ and $300 \mathrm{~ms}$, priming caused increased negativity at inferior temporal electrodes, particularly over the left hemisphere $\left(\mathrm{FT}_{9}, \mathrm{TP}_{9}, \mathrm{P}_{9}, \mathrm{PO}_{9}\right)$ and increased positivity at midfrontal electrodes (e.g., $\mathrm{F}_{\mathrm{Z}}$ ); (c) between approximately 300 and $500 \mathrm{~ms}$, priming caused less negative ERPs at parietal and central sites $\left(\mathrm{C}_{\mathrm{Z}}\right.$,
$\left.\mathrm{P}_{\mathrm{Z}}, \mathrm{C}_{3}, \mathrm{C}_{4}, \mathrm{P}_{3}, \mathrm{P}_{4}\right)$ and more negative ERPs at prefrontal sites $\left(\mathrm{Fp}_{1}\right.$, $\left.\mathrm{Fp}_{2}, \mathrm{~F}_{9}{ }^{\prime}, \mathrm{F}_{10}{ }^{\prime}\right)$.

To determine more formally whether the ERP priming effects in these time segments were topographically dissociable from one another, we first calculated the three difference waveforms primed same minus unprimed (PS-UP), primed different minus unprimed (PD-UP), and primed same minus primed different (PS-PD). For each difference wave we then scaled mean amplitudes for each participant across all electrodes, with the average distance of the mean, calculated from the grand mean ERPs, as the divisor (McCarthy \& Wood, 1985). We then performed an initial ANOVA on these scaled amplitudes for the PS-UP difference, with one factor time segment ( 3 levels) and a second factor electrode site (32 levels). The topography of the PS-UP difference changed qualitatively across these three time segments, $F(62,682)=6.1, p<$ .001 . Bonferroni-corrected pairwise comparisons revealed that the topography of the PS-UP difference changed qualitatively from the $180-220-\mathrm{ms}$ to the $220-300-\mathrm{ms}$ segment, $F(31,341)=8.1$, $p<.001$, and again from the 220-300-ms to the 300-400-ms segment, $F(31,341)=3.9, p<.01$ (see Figure 4 ; the topographies of this difference were also significantly different between the $180-220-\mathrm{ms}$ and the 300-400-ms segments, $F[31,341]=6.6$, $p<.001)$. This confirms that the three priming effects we observed were indeed qualitatively different.

The PS-PD difference appeared to contain only the earliest of these effects. Its topography did not change from the 180-220-ms to the 220-300-ms segments, $F(31,341)<1$ (see Figure 4), and the effect had vanished after $300 \mathrm{~ms}$. This suggests that the effect of identical stimulus repetition seen in the 180-220-ms segment persisted until about $300 \mathrm{~ms}$ but vanished thereafter. One should note that in the 180-220-ms segment, the PS-UP difference and the PS-PD difference were comparable in topography, $F(31$, $341)<1$ (see Figure 4).

Although there was no significant PD-UP difference in the 180-220-ms segment, the topography of the PD-UP difference also changed qualitatively from the $220-300-\mathrm{ms}$ to the $300-$ 400-ms segment, $F(31,341)=4.7, p<.01$.

When differences between conditions were compared within the same time segment, it turned out that the PS-UP and PD-UP differences were topographically indistinguishable in the $300-$ 400-ms segment, $F(31,341)<1$. In the $220-300$-ms segment, the PS-UP and the PD-UP differences also did not show clearly different topographies, $F(31,341)=1.8, p>.10$. It may be initially surprising that a larger amplitude difference was seen for the primed-different condition, relative to the primed-same conditions (see Figure 2 and the mean amplitude analyses reported

\footnotetext{
${ }^{3}$ However, one should note that priming effects sometimes inverted polarity across sites within a region, and these effects would not be picked up by the overall priming effect for a region. For instance, for frontalcentral sites primed names caused more negative ERPs from 400-500 ms at frontal $\left(\mathrm{F}_{3}, \mathrm{~F}_{\mathrm{Z}}, \mathrm{F}_{4}\right)$ electrodes but more positive ERPs at frontal-central electrodes $\left(\mathrm{C}_{3}{ }^{\prime}, \mathrm{C}_{4}{ }^{\prime}\right)$. This effect was reflected in a significant priming by electrode interaction for the frontal-central analysis, $F(8,88)=9.7, p<$ .001. Similarly, for temporal sites primed names caused more negative ERPs from 400-500 ms at more inferior electrodes $\left(\mathrm{TP}_{9}, \mathrm{TP}_{10}\right)$, but more positive ERPs at more superior electrodes $\left(\mathrm{P}_{7}, \mathrm{P}_{8}\right)$, yielding a significant Priming $\times$ Electrode interaction for the temporal analysis, $F(14,154)=$ 4.5, $p<.01$.
} 
above). However, the PS-PD difference that captures the fontspecific effect (see Figure 4) indicates that this effect not only persists in the 220-300 ms segment but is also almost opposite in polarity to the N250r effect that occurs in the absence of font repetition (i.e., in the PD-UP difference). Thus, the most likely explanation for the smaller amplitude of N250r for the primedsame condition than for the primed-different conditions is a temporal overlap with the preceding font-specific repetition effect.

\section{Discussion}

Experiment 1 revealed three ERP modulations due to the repetition of familiar written names. First, a posterior negativity was seen in the N200 component (180-220 ms). This N200 effect only occurred for exact (i.e., same-font) name repetitions. Second, a left temporal N250 repetition effect (N250r) was observed for both same-font and different-font repetitions. Finally, an N400-type modulation was observed for both same-font and different-font repetitions alike.

We propose that the N200 effect is a correlate of font-specific featural processing, as it is completely absent when a different font is used to represent the same name at target (see Figures 2B and 4). The peak latency of the effect, at $200 \mathrm{~ms}$, is almost $100 \mathrm{~ms}$ after the $\mathrm{P}_{1}$, a prominent positive visually evoked potential that is generated in extrastriate visual areas (Clark, Fan, \& Hillyard, 1995). Of particular interest, intracranial recordings have identified an ERP response in ventral temporal (e.g., fusiform) areas to letter-string stimuli at approximately 200-ms latency (Allison, McCarthy, Nobre, Puce, \& Belger, 1994). This intracranial N200 was independent of whether these were words or pseudowords, suggesting a prelexical locus at the processing of the stimulus features. Although it is difficult at present to directly relate the present scalp-recorded N200 effect to the intracranial N200, our findings are additional evidence for activation related to the processing of letter-strings at around $200 \mathrm{~ms}$ in posterior neocortex. If the interpretation of the $\mathrm{N} 200$ in terms of a facilitation at a prelexical font-specific stage is correct, an interesting and testable prediction would be that the same effects should be seen when comparing same-font versus different-font repetitions for unfamiliar names or pseudowords as well. An additional observation is that the activation reflected by the N200 modulation extends in time until about $300 \mathrm{~ms}$. Thus, our results suggest that the N200 effect overlaps in time with the N250r effect (see also Figure 4 and our discussion above). This finding could be interpreted as neurophysiological evidence that font-specific featural and lexical processes are organized in cascades (McClelland, 1979) rather than in a strictly serial fashion.

Whereas the N200 effect appears to be specific for names repeated in the same font, the N250r is present for repetitions of the same name across both the same font and different fonts (see Figure 2C and Figure 4). Other studies have established that the N250r component is sensitive to person familiarity (Pfütze et al., 2002; Schweinberger et al., 1995). Therefore, we suggest that N250r in Experiment 1 reflects a late stage in the perceptual processing of personal names. Within a structural model, this could be at the level of access to abstract visual representations for names (defined as name recognition units [NRUs] by Valentine et al., 1991).
It is important to note that the priming effects reflected in N250r (measured in the 220-300-ms segment) were larger over left than right temporal regions. Left lateralization was significant when comparing left and right hemisphere homologous electrodes $\mathrm{FT}_{9}$ and $\mathrm{FT}_{10}$, priming by hemisphere interaction, $F(1,11)=9.8, p<$ .01 (primed different versus unprimed), and it approached significance for electrodes $\mathrm{TP}_{9}$ and $\mathrm{TP}_{10}, F(1,11)=4.3, p=.06 .{ }^{4}$ This result is in line with considerable evidence for a left hemisphere superiority in the recognition of personal names, from behavioral studies (Schweinberger, Kaufmann, \& McColl, 2002; Schweinberger, Landgrebe, Mohr, \& Kaufmann, 2002; but see VanLancker \& Ohnesorge, 2002), ERP and brain-imaging studies (GornoTempini et al., 1998; Grabowski et al., 2001; Proverbio et al., 2001; Sergent, MacDonald, \& Zuck, 1994), and brain-lesioned studies of patients (Newcombe, DeHaan, Ross, \& Young, 1989; Schweinberger, 1995). Further, there is evidence that the N250r is right-lateralized for faces (Schweinberger et al., 1995), suggesting that it reflects modality-specific processes. If N250r is a correlate of the access to abstract visual representations for names (i.e., NRUs), then it should not be observed when faces, which should not activate NRUs, are used as primes.

The N400 modulation observed in Experiment 1 is likely to reflect semantic processing, a suggestion that is consistent with

\footnotetext{
${ }^{4} \mathrm{We}$ also used dipole source analysis in an attempt to determine the potential loci of generators of the N250r. Dipole source models were determined by using the Brain Electromagnetic Source Analysis program (BESA2000; Scherg \& Berg, 2000) with the four-shell spherical head model (i.e., brain, bone, cerebrospinal fluid, and scalp). Primarily, a source model is derived by fitting the source model iteratively to the data until a minimum in residual variance $(\mathrm{RV})$ is reached (i.e., the percentage of variance in the recorded potential distribution not accounted for by the source model is minimized). To limit the number of parameters estimated, we applied symmetry constraints to the location of bilateral dipole pairs No other constraints with respect to localization were used. To localize the possible generators of the N250r, the difference waves (grand averages across subjects) of the PD-UP difference was used, because this showed the largest amplitudes as discussed above. Spatial principal component analysis (PCA) was used to determine the minimum number of dipole pairs to be included in the model. An epoch of 256-288 ms after stimulus onset yielded the clearest solution both in terms of contributing components and residual variance. A PCA showed that one principal component (PC) explained $99.5 \%$ of variance (a second PC explained only $0.4 \%$ ) in this epoch, therefore only one dipole pair was fitted. The subsequent solution accounted for almost all variance-RV was $1.8 \%$. The dipole pair was located in ventral temporal areas, in the fusiform gyrus $(x= \pm 36 \mathrm{~mm}, y=$ $-22 \mathrm{~mm}, z=33 \mathrm{~mm}$, in BESA2000 coordinates, corresponding to $x=$ $\pm 36 \mathrm{~mm}, y=-43 \mathrm{~mm}, z=-6 \mathrm{~mm}$, in Talairach \& Tournoux, 1988 coordinates). Of particular interest, this location is almost identical to that seen for the immediate repetition of faces, which also causes an N250r modulation, although one that tends to be larger over the right hemisphere (Schweinberger, Pickering, Jentzsch, et al., 2002). These locations appear to be broadly consistent with findings from intracranial recordings, which suggest that different but nearby areas within fusiform cortex produce either face-specific or word-specific responses in roughly this time range (Allison, Puce, Spencer, \& McCarthy, 1999). We also performed additional exploratory dipole source analyses for the N200 and N400 components. However, the solutions were not entirely satisfactory, in terms of residual variances of $5 \%$ or larger, and these analyses are therefore not reported further.
} 
previous literature (Bentin \& McCarthy, 1994; Rugg, 1987). In an associative priming study, Schweinberger (1996) found that N400type modulations for faces and names were qualitatively indistinguishable. Further, in a study that compared repetition priming for familiar faces and names (with hundreds of stimuli intervening between repetitions), N400 modulations were equivalent for both stimulus modalities, suggesting that neither modality-specific nor transient processes were reflected in this component (Schweinberger, Pickering, Burton, \& Kaufmann, 2002). Cross-modality priming, termed by some self priming (Calder \& Young, 1996) or semantic repetition priming, is thought to be mediated by facilitated access to semantic information. On the basis of our interpretation of the functional significance of the N250r and N400 components in Experiment 1, we predicted that (a) the N400 effect observed for primed names will be preserved for names primed in a different modality (e.g., Bill Clinton's name primed by his face) but that (b) the N250r effect will be eliminated under these conditions.

We note the N250r and the N400 showed an equivalent pattern of effects in Experiment 1, in that both components were sensitive to repetition irrespective of font changes. Thus, the data from Experiment 1 per se do not convincingly support the interpretation of the N250r and N400 as related to the levels of NRUs and semantic processing, respectively. For instance, one concern could be that N250r is influenced by semantic processing as well. We therefore performed an additional experiment in which we investigated immediate priming of target names, using faces as prime stimuli. Cross-modality repetition priming should facilitate postperceptual semantic processing, but not earlier perceptual processing of names (Calder \& Young, 1996; Calder, Young, Benson, \& Perrett, 1996). Thus, we expected to see an N400 modulation similar to the one seen for within-modality priming. In addition, we hypothesized that to the extent that the N250r modulation reflects a facilitation of semantic processing, it should also be seen when a familiar name has been preceded by the face of the same celebrity. In contrast, we hypothesized that if the N250r modulation reflects a facilitation of modality-specific processing at the level of abstract RUs for names, this ERP effect should be absent when the face of the corresponding celebrity precedes a familiar name.

\section{Experiment 2}

\section{Method}

Participants. The same 12 participants who took part in Experiment 1 also contributed data to Experiment 2. The order of the experiments was counterbalanced across participants.

Stimuli and apparatus. The 90 famous and 90 unfamiliar target names used in Experiment 1 were also presented as targets in this experiment; however, prime stimuli were the faces of the 90 celebrities whose names were used as targets. Target names were divided into three sets (with 30 names each) so that the proportion of primed to unprimed trials (60 to 30) could be kept the same as in Experiment 1. Also, assignment of name set to experimental condition could be counterbalanced across participants in the same way as for Experiment 1. As we had two photographs of each celebrity available, experimental conditions were now unprimed, primed by Face A, and primed by Face B. However, to use equal numbers of trials per condition, the condition primed by Face B was considered a filler condition, and only the conditions unprimed and primed by Face A were subjected to analysis.

Procedure and data acquisition. The procedure was analogous to that for Experiment 1, except that famous faces were presented as prime stimuli. Participants received written task instructions before the experiment and then completed 16 practice trials. The prime faces and target names shown for practice trials were not presented subsequently. The duration of trials and timings of stimulus presentation were the same as for Experiment 1. Performance and ERP data were collected in the same way as in Experiment 1. Participants performed blink and eye-movement calibration trials (described in the Procedure section for Experiment 1) between experiments, and these trials were used to correct ocular artifacts in both experiments.

\section{Results}

Performance. Mean error rates and RTs to familiar target names are shown in Table 2. No omissions were observed. Table 2 shows that error rates were low $(M=4.9 \%)$.

Correct RTs and error rates to familiar names were submitted to ANOVAs with repeated measures on priming condition (unprimed vs. primed). We performed epsilon corrections for heterogeneity of covariances, using the Huynh-Feldt method (Huynh \& Feldt, 1976) throughout.

The ANOVA on RTs revealed a significant effect of priming, $F(1,11)=34.8, p<.001$. The ANOVA on error rates also revealed a significant effect of priming, $F(1,11)=8.4, p<.05$. As expected, both effects reflect more efficient processing of primed names.

ERPs. ERPs to target names were quantified by mean amplitude measures in the same time segments as in Experiment 1; all amplitude measures were taken relative to a 200-ms baseline preceding the target stimulus. ANOVAs were then performed analogous to those in Experiment 1, except that priming was now a two-level factor

Figure 3 shows the cross-modality priming effects for famous names. No significant priming effects were observed in the 110 140 -ms segment, $F(31,341)<1.4$. In contrast to Experiment 1, priming effects were also completely absent at 180-220 ms and at 220-300 ms, $F s(31,341)<1$. Nevertheless, an inspection of left temporal sites in Figure 3 suggests that cross-modality priming may have caused some effect on the N250r, which, although much smaller, was qualitatively similar to that seen for within-modality priming in Experiment 1. Because our ANOVA of all electrodes can be argued to be relatively conservative, the question may arise whether more specific analyses of the left temporal region would reveal a small effect of cross-modality priming on the N250r. Such a finding would weaken the idea that the N250r is completely insensitive to semantic processing. For the 220-300-ms segment

Table 2

Mean Reaction Times (RTs, in $\mathrm{ms}$ ) and Percentages of Errors (PEs) for Target Names in Experiment 2

\begin{tabular}{ccc}
\hline Target names and conditions & RT & PE \\
\hline Famous names & & \\
Unprimed & 772 & 7.6 \\
Primed & 647 & 2.1 \\
Unfamiliar names & 785 & 4.1 \\
\hline
\end{tabular}




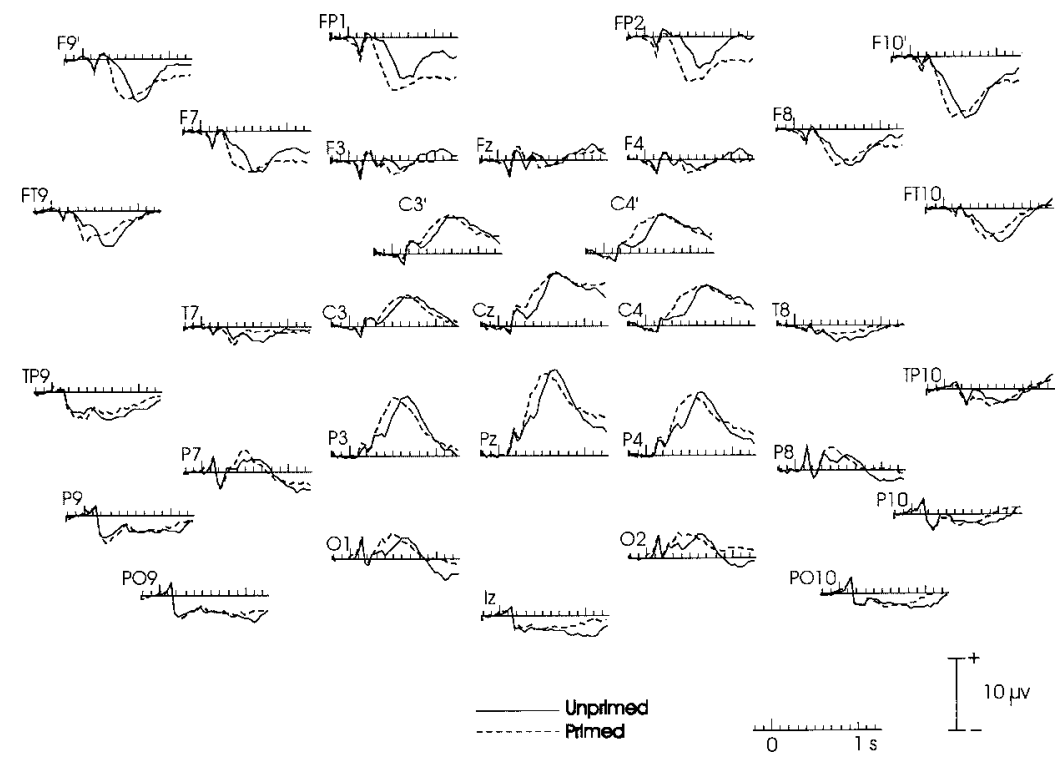

Figure 3. ERPs (event-related potentials) in Experiment 2 recorded for familiar target names that were unprimed (solid lines) or cross-modality repetition primed (i.e., that had been preceded by the corresponding celebrity's face; dashed lines). Recordings are shown for all 32 electrode sites used.

we therefore performed more specific analyses of the left temporal $\mathrm{FT}_{9}, \mathrm{TP}_{9}$, and $\mathrm{P}_{9}$ electrodes only (for N250r amplitudes at these sites, see also Table 3). ${ }^{5}$ First, we ran an additional ANOVA between experiments involving the factors prime modality (within vs. across modalities), priming (primed vs. unprimed), and electrode $\left(\mathrm{FT}_{9}, \mathrm{TP}_{9}, \mathrm{P}_{9}\right)$. (As a comparison to the cross-modality condition in Experiment 2, the primed-different condition from Experiment 1 was used, to exclude any contribution of stimulus repetition per se.) As expected, this ANOVA revealed a significant priming effect at left temporal sites, $F(1,11)=13.2, p<.01$, as well as a significant Prime Modality $\times$ Priming interaction, $F(1$, $11)=6.4, p<.05$. Whereas there were clear effects of withinmodality priming, $F(1,11)=14.3, p<.01$, there were no significant effects of cross-modality priming, $F(1,11)=2.7, p=$ .13 , even when tested at left temporal sites only.

Significant cross-modality priming effects were observed only in the time segments between $300 \mathrm{~ms}$ and $500 \mathrm{~ms}(300-400 \mathrm{~ms}$, $F[31,341]=6.5, p<.001 ; 400-500 \mathrm{~ms}, F[31,341]=9.4, p<$ $.001)$. In the subsequent time segments, priming effects were diminished to insignificance, $F(31,341)=2.4, p>.05$, and $F(31$, $341)=1.3, p>.10$, for the 500-600-ms and 600-700-ms segments, respectively. The priming effects between $300 \mathrm{~ms}$ and $500 \mathrm{~ms}$ were similar to the central-parietal N400 effects seen in Experiment 1 (cf. Figures 2 and 3).

To evaluate this impression, we performed an additional ANOVA between experiments involving the factors prime modality (within vs. across modalities), priming (primed vs. unprimed), and electrode site (32 levels). Significant priming effects were observed across experiments between $300 \mathrm{~ms}$ and $500 \mathrm{~ms}$ (300$400 \mathrm{~ms}, F[31,341]=9.2, p<.001 ; 400-500 \mathrm{~ms}, F[31,341]=$ 17.8, $p<.001)$. Most important, these priming effects did not differ significantly between prime modalities, $F_{\mathrm{s}}(31,341)<1.5$, $p s>$.10. A comparison of the scaled differences between the primed and unprimed conditions between experiments also did not suggest topographically different effects of within- versus crossmodality priming, $F \mathrm{~s}(31,341)<1.4, p \mathrm{~s}>.10$ (see Figure 4).

\section{Discussion}

The results of this experiment show that cross-modal repetition priming of names elicited a clear N400 priming effect (see Figure 4), which was indistinguishable from the N400 recorded for both same-font and different-font name repetitions in Experiment 1. Our results concur with studies that have shown N400 priming effects to be related to the semantic characteristics of primed stimuli (e.g., Bentin et al., 1985). In contrast, the present data did not suggest any effects of cross-modal repetition priming on the N200 or the N250r components. This is in line with the interpretation of the N200 and N250r priming effects discussed above. Specifically, it suggests that the N250r is not influenced by semantic processing, corroborating the idea that this component reflects a facilitation at the access to relatively font-independent but modality-specific NRUs.

Although a visual inspection of the ERPs in Experiment 2 suggests that a small effect of cross-modality priming on the N250r may have been present, such an effect was not statistically significant, even when tested for the left temporal region at which N250r was most clear for within-modality priming. Nevertheless, because cross-modality priming at left temporal regions was almost a statistical trend ( $p=.13$ ), we do not wish to make a strong case for a null effect. However, one should remember that the SOA of $1.8 \mathrm{~s}$ clearly provided sufficient time for strategic expectations with respect to the target name, and the use of strategies may have been likely because the repetition proportion of our trials was high (i.e., for familiar targets, 50\%). Strategic effects-such as the

\footnotetext{
${ }^{5}$ We thank an anonymous reviewer for this suggestion.
} 
Table 3

Mean Event-Related Potentials Priming Effects (in $\mu V$ ) at LTEs and RTEs for the 220-300-ms segment (N250r)

\begin{tabular}{lcc}
\hline & Experiment 1 & Experiment 2 \\
Scalp position & (within-modality priming) & (cross-modality priming) \\
\hline
\end{tabular}

\section{LTE}

\begin{tabular}{lll}
$\mathrm{FT}_{9}$ & -1.02 & -0.30 \\
$\mathrm{TP}_{9}$ & -1.01 & -0.57 \\
$\mathrm{P}_{9}$ & -1.30 & -0.69 \\
Mean - LTEs & -1.11 & -0.52 \\
\hline
\end{tabular}

RTE

$\begin{array}{lrr}\mathrm{FT}_{10} & 0.14 & 0.06 \\ \mathrm{TP}_{10} & -0.66 & -0.45 \\ \mathrm{P}_{10} & -0.40 & -0.09 \\ \text { Mean - RTEs } & -0.31 & -0.16\end{array}$

Note. Data show amplitude differences between primed and unprimed conditions for within-modality priming (different-font condition) in Experiment 1 and for cross-modality priming in Experiment 2. LTE $=$ left temporal electrode; $\mathrm{RTE}=$ right temporal electrode.

visual imagery of a celebrity's name upon the presentation of a prime face-might therefore mediate an effect of cross-modality repetition on the N250r. Although this interesting possibility is open to future study, the present data suggest that any such contribution to the N250r was negligible in the present study.

\section{General Discussion}

In two experiments that assessed the ERP effects of the priming of personal names, we have identified three distinct and dissociable loci of priming.

When a name was repeated in the same font, form-specific processes were reflected in an early negative component around $200 \mathrm{~ms}$, visible over midline posterior electrode sites. We suggest that this N200 component reflects facilitation in font-specific featural processing. At present it is difficult to directly relate this font-specific ERP repetition effect to known effects in the ERP literature. However, it is noteworthy that ERP modulations over posterior areas - although with a different polarity and somewhat longer latency in excess of $300 \mathrm{~ms}$ - have been previously related to priming of visual word form. For example, a recent ERP study investigated priming of visual word form using a reading manipulation in which prime words either appeared in a backward format (e.g., $d-r-o-w)$ or in the usual forward format. In this study, which used a longer lag of 5-9 items intervening between prime and target, a symmetric ERP effect over posterior cortex was related to priming of visual word form (Paller \& Gross, 1998). A similar posterior ERP effect was obtained when contrasting ERPs to targets that were primed either by full words or by words presented in a letter-by-letter fashion (Paller, Kutas, \& McIsaac, 1998).

In both the present data and the findings by Paller and colleagues (Paller \& Gross, 1998; Paller et al., 1998), the posterior ERP effect due to repetition of the exact stimulus was approximately symmetric. This may be seen in some contrast to a considerable body of evidence suggesting that the form-specific priming system operates mainly in the right hemisphere (Marsolek et al., 1992). At present it is difficult to determine whether this discrepancy relates to differences in experimental task, differences in sample of participants, or a geometry of ERP generators that makes a strong lateralization in scalp recordings unlikely. With respect to participants, one may note that the majority of our participants were female, whereas Marsolek et al. (1992) used an all-male sample, as there seems to be a greater degree of lateralization of function in men than women (McGlone, 1980). It will also be interesting to see whether the form-specific ERP priming effect shown in this study is also found under different tasks, for example, when participants perform word stem completion or perceptual identification tasks (Bowers, 1996; Marsolek et al., 1992). Perhaps most significant, the present study investigated immediate repetition priming, whereas those studies that demonstrated a right hemisphere advantage for form-specific priming typically used much longer intervals between prime and target. In that respect, it is noteworthy that when using longer intervals between prime and target, we have also recently reported evidence from ERPs for right hemisphere involvement in form-specific repetition priming (Schweinberger, Pickering, Burton, \& Kaufmann, 2002).

We also found that the N250r was present for same-font and different-font name repetitions but was absent when names were primed by faces. Further, in this study, N250r appeared to be larger over left-hemisphere electrode sites. This is an interesting contrast to earlier studies demonstrating a right-lateralized N250r for faces (Pfütze et al., 2002; Schweinberger et al., 1995). It is also worth noting that in a study analogous to the present Experiment 1 but with faces as stimuli, the face-elicited N250r was nearly three times as large in amplitude as the present name-elicited N250r (Schweinberger, Pickering, Jentzsch, et al., 2002). Given that the

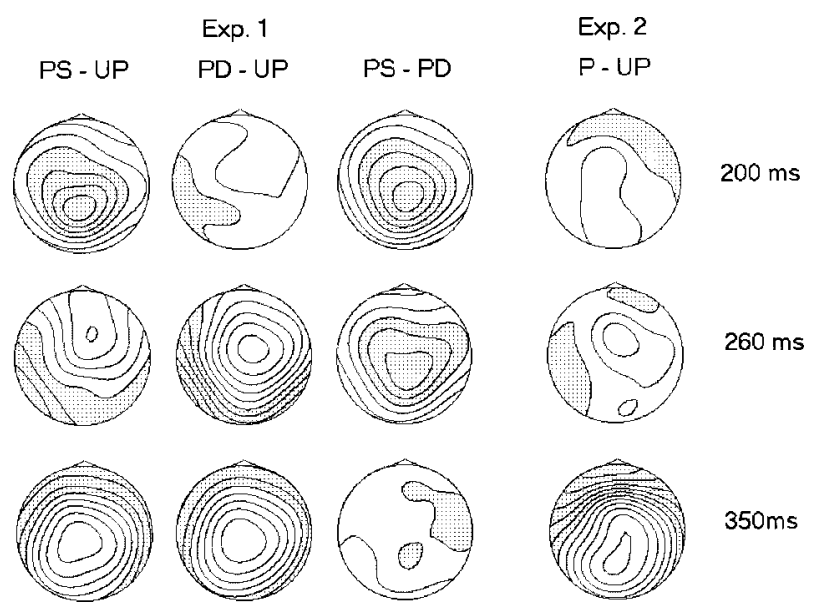

Figure 4. Topographical voltage maps of ERP (event-related potential) differences between primed and unprimed conditions show the three qualitatively different priming effects at $200 \mathrm{~ms}$ (N200), $260 \mathrm{~ms}$ (N250r) and $350 \mathrm{~ms}$ (N400). All maps were obtained by using spherical spline interpolation (Perrin, Pernier, Bertrand, \& Echallier, 1989). Equipotential lines are separated by $0.5 \mu \mathrm{V} /$ line. Negativity is shaded. PS-UP $=$ difference primed same minus unprimed (Experiment 1); PD-UP = difference primed different minus unprimed (Experiment 1); PS-PD $=$ difference primed same minus primed different (Experiment 1); P-UP $=$ difference primed minus unprimed for cross-modality priming (Experiment 2). 
name-elicited N250r is present for both same-font and differentfont repetitions, and that it is larger over left hemisphere sites, we suggest that this component is related to early stages of abstractive priming and reflects facilitation at the level of modality-specific RUs for familiar names (Valentine et al., 1991).

Modulation of the N400 component has been consistently observed in both repetition-priming and semantic-priming experiments, and in this study, topographic analyses have shown that the N400 priming effect was equivalent whether names were repeated or primed by faces. Through the second experiment, we have been able to isolate this correlate of semantic memory retrieval from ERP effects that we suggest are related to form-specific and abstractive priming. The IAC model of person recognition (Burton et al., 1990, 1999) proposes that modality-specific representations (e.g., FRUs or NRUs) must be activated before semantic information about a person is accessed (via a common route). Consistent with this model, we have found ERP evidence for a modalityspecific processing stage that is qualitatively different from later semantic processes.

It is noteworthy that some research into the N400 ERP component has suggested that the neural generators for the effects with different stimulus modalities are nonidentical, implying that semantic knowledge might not be stored in a modality-independent manner (for a recent review, see Kutas \& Federmeier, 2000). For example, recent studies found topographical differences between N400 responses to pictures of objects and common names (Ganis, Kutas, \& Sereno, 1996; McPherson \& Holcomb, 1999). The present data do not suggest differences between N400 responses for cross-modality and within-modality priming. This result appears to be in some contrast to the findings mentioned above and seems to support the idea that semantic information about people is stored independent of the precise perceptual input (Burton et al., 1990; Schweinberger, 1996). However, a different pattern of results for objects and common names as compared with faces and personal names is not necessarily in strong contradiction, because evidence exists for a neuropsychological dissociation of semantic memory for common words and objects versus semantic memory for unique items (e.g., faces, personal names, or famous landmarks; Kartsounis \& Shallice, 1996) or people (Hanley, Young, \& Pearson, 1989). Moreover, a recent functional magnetic resonance imaging (fMRI) study suggested not only that familiar faces elicit increased activity in retrosplenial cortex relative to unfamiliar faces but also that the same site of activation is seen for familiar relative to unfamiliar voices (Shah et al., 2001). Together with the present findings, such data support the idea that following stimulus and modality-specific perceptual analysis, information then converges into common and modality-independent processes of person recognition.

In the context of the present study, it is also worth mentioning that other neurophysiological techniques have produced compelling evidence of multiple priming processes. When a stimulus is repeated, cells that respond preferentially to that item show a decrease in levels of activation, termed repetition suppression, as seen in the inferior temporal (IT) cortex of monkeys (Brown, Wilson, \& Riches, 1987; Miller, Li, \& Desimone, 1991) and in several cortical regions for humans (e.g., Schacter, Alpert, Savage, Rauch, \& Albert, 1996; Squire et al., 1992). Repetition suppression is widely considered as a neural correlate of perceptual priming (Naccache \& Dehaene, 2001; Schacter \& Buckner, 1998). How- ever, intracranial recordings from monkey IT cortex have also revealed a class of stimulus-selective cells that show repetition enhancement when an item's repetition is behaviorally relevant but not when repetitions are irrelevant (Miller \& Desimone, 1994). Task-mediated repetition enhancement has also been described in humans (e.g., the fMRI findings of Henson, Shallice, GornoTempini, \& Dolan, 2002). These results support the notion of multiple neural correlates of priming, and although we acknowledge that at present it is difficult to directly relate findings from scalp-recorded ERPs to the phenomena of repetition suppression and repetition enhancement, this issue seems worthy of further investigation.

Behavioral studies have used a varied range of response measures, tasks, and stimuli to show that priming can affect multiple processing stages. ERP measurement can provide a much more precise picture of the time ranges in which separate processes occur. The recording of ERP measures across the range of paradigms used in behavioral research may help to further discriminate between these processes. This present study of name recognition highlights the power of ERPs to fractionate separate feature-based, lexical, and semantic processing stages that are sensitive to priming.

\section{References}

Abdel Rahman, R., Sommer, W., \& Schweinberger, S. R. (2002). Brainpotential evidence for the time course of access to biographical facts and names of familiar persons. Journal of Experimental Psychology: Learning, Memory, and Cognition, 28, 366-373.

Allison, T., McCarthy, G., Nobre, A., Puce, A., \& Belger, A. (1994). Human extrastriate visual cortex and the perception of faces, words, numbers, and colors. Cerebral Cortex, 5, 544-554.

Allison, T., Puce, A., Spencer, D. D., \& McCarthy, G. (1999). Electrophysiological studies of human face perception: I. Potentials generated in occipitotemporal cortex by face and non-face stimuli. Cerebral Cortex, 9, 415-430.

Begleiter, H., Porjesz, B., \& Wang, W. Y. (1995). Event-related brain potentials differentiate priming and recognition to familiar and unfamiliar faces. Electroencephalography and Clinical Neurophysiology, 94, 41-49.

Bentin, S., \& McCarthy, G. (1994). The effects of immediate stimulus repetition on reaction time and event-related potentials in tasks of different complexity. Journal of Experimental Psychology: Learning, Memory, and Cognition, 20, 130-149.

Bentin, S., McCarthy, G., \& Wood, C. C. (1985). Event related potentials, lexical decision and semantic priming. Electroencephalography and Clinical Neurophysiology, 60, 343-355.

Bentin, S., \& Moscovitch, M. (1988). The time course of repetition effects for words and unfamiliar faces. Journal of Experimental Psychology: General, 117, 148-160.

Bowers, J. S. (1996). Different perceptual codes support priming for words and pseudowords: Was Morton right all along? Journal of Experimental Psychology: Learning, Memory, and Cognition, 22, 1336-1353.

Brédart, S. (1993). Retrieval failures in face naming. Memory, 1, 351-366.

Brédart, S., Brennen, T., \& Valentine, T. (1997). Dissociations between the processing of proper and common names. Cognitive Neuropsychology, 14, 209-217.

Brennen, T. (1993). The difficulty with recalling people's names: The plausible phonology hypothesis. Memory, 1, 409-431.

Brooks, B. E., Rosielle, L. J., \& Cooper, E. E. (2002). The priming of face recognition after metric transformations. Perception, 31, 297-313.

Brown, M. W., Wilson, F. A. W., \& Riches, I. P. (1987). Neuronal 
evidence that inferomedial temporal cortex is more important than hippocampus in certain processes underlying recognition memory. Brain Research, 409, 158-162.

Bruce, V., Carson, D., Burton, A. M., \& Kelly, S. W. (1998). Prime-time advertisements: Repetition priming from faces seen on subject recruitment posters. Memory \& Cognition, 26, 502-515.

Bruce, V., \& Valentine, T. (1985). Identity priming in the recognition of familiar faces. British Journal of Psychology, 76, 373-383.

Bruce, V., \& Young, A. (1986). Understanding face recognition. British Journal of Psychology, 77, 305-327.

Burgund, E. D., \& Marsolek, C. J. (1997). Letter-case-specific priming in the right cerebral hemisphere with a form-specific perceptual identification task. Brain and Cognition, 35, 239-258.

Burton, A. M., \& Bruce, V. (1992). I recognize your face but I can't remember your name: A simple explanation? British Journal of Psychology, 83, 45-60.

Burton, A. M., Bruce, V., \& Hancock, P. J. B. (1999). From pixels to people: A model of familiar face recognition. Cognitive Science, 23, $1-31$.

Burton, A. M., Bruce, V., \& Johnston, R. A. (1990). Understanding face recognition with an interactive activation model. British Journal of Psychology, 81, 361-380.

Burton, A. M., Kelly, S. W., \& Bruce, V. (1998). Cross-domain repetition priming in person recognition. The Quarterly Journal of Experimental Psychology: Human Experimental Psychology, 51(A), 515-529.

Calder, A. J., \& Young, A. W. (1996). Self priming: A short-term benefit of repetition. The Quarterly Journal of Experimental Psychology: Human Experimental Psychology, 49(A), 845-861.

Calder, A. J., Young, A. W., Benson, P. J., \& Perrett, D. I. (1996). Self priming from distinctive and caricatured faces. British Journal of Psychology, 87, 141-162.

Clark, V. P., Fan, S., \& Hillyard, S. A. (1995). Identification of early visual evoked potential generators by retinotopic and topographic analyses. Human Brain Mapping, 2, 170-187.

Clarke, R., \& Morton, J. (1983). Cross modality facilitation in tachistoscopic word recognition. The Quarterly Journal of Experimental Psychology: Human Experimental Psychology, 35(A), 79-96.

Cohen, G. (1990). Why is it difficult to put names to faces? British Journal of Psychology, 81, 287-297.

Dehaene, S. (1995). Electrophysiological evidence for category-specific word processing in the normal human brain. NeuroReport, 6, 21532157.

Dehaene, S., Naccache, L., Cohen, L., Le Bihan, D., Mangin, J. F., Poline, J. B., et al. (2001). Cerebral mechanisms of word masking and unconscious repetition priming. Nature Neuroscience, 4, 752-758.

Doyle, M. C., Rugg, M. D., \& Wells, T. (1996). A comparison of the electrophysiological effects of formal and repetition priming. Psychophysiology, 33, 132-147.

Elbert, T., Lutzenberger, W., Rockstroh, B., \& Birbaumer, N. (1985). Removal of ocular artifacts from the EEG-A biophysical approach to the EOG. Electroencephalography and Clinical Neurophysiology, 60, $455-463$.

Ellis, A. W., Flude, B. M., Young, A., \& Burton, A. M. (1996). Two loci of repetition priming in the recognition of familiar faces. Journal of Experimental Psychology: Learning, Memory, and Cognition, 22, 295308

Ellis, A. W., Young, A. W., \& Flude, B. (1990). Repetition priming and face processing: Priming occurs within the system that responds to the identity of a face. The Quarterly Journal of Experimental Psychology: Human Experimental Psychology, 42(A), 495-512.

Feustel, T. C., Shiffrin, R. M., \& Salasoo, A. (1983). Episodic and lexical contributions to the repetition effect in word identification. Journal of Experimental Psychology: General, 112, 309-346.

Ganis, G., Kutas, M., \& Sereno, M. I. (1996). The search for "common sense": An electrophysiological study of the comprehension of words and pictures in reading. Journal of Cognitive Neuroscience, 8, 89-106.

Gorno-Tempini, M. L., Price, C. J., Josephs, O., Vandenberghe, R., Cappa, S. F., Kapur, N., et al. (1998). The neural systems sustaining face and proper-name processing. Brain, 121, 2103-2118.

Grabowski, T. J., Damasio, H., Tranel, D., Ponto, L. L. B., Hichwa, R. D., \& Damasio, A. R. (2001). A role for left temporal pole in the retrieval of words for unique entities. Human Brain Mapping, 13, 199-212.

Hanley, J. R., Young, A. W., \& Pearson, N. A. (1989). Defective recognition of familiar people. Cognitive Neuropsychology, 6, 179-210.

Henson, R. N. A., Shallice, T., Gorno-Tempini, M. L., \& Dolan, R. J. (2002). Face repetition effects in implicit and explicit memory tests as measured by fMRI. Cerebral Cortex, 12, 178-186.

Hollis, J., \& Valentine, T. (2001). Proper-name processing: Are proper names pure referencing expressions? Journal of Experimental Psychology: Learning, Memory, and Cognition, 27, 99-116.

Huynh, H., \& Feldt, L. S. (1976). Estimation of the Box correction for degrees of freedom from sample data in randomized block and split-plot designs. Journal of Educational Statistics, 1, 69-82.

Jacoby, L. L., \& Hayman, C. A. G. (1987). Specific visual transfer in word identification. Journal of Experimental Psychology: Learning, Memory, and Cognition, 13, 456-463.

Joyce, C. A., Paller, K. A., Schwartz, T. J., \& Kutas, M. (1999). An electrophysiological analysis of modality-specific aspects of word repetition. Psychophysiology, 36, 655-665.

Kartsounis, L. D., \& Shallice, T. (1996). Modality specific semantic knowledge loss for unique items. Cortex, 32, 109-119.

Koutstaal, W., Wagner, A. D., Rotte, M., Maril, A., Buckner, R. L., \& Schacter, D. L. (2001). Perceptual specificity in visual object priming: Functional magnetic resonance imaging evidence for a laterality difference in fusiform cortex. Neuropsychologia, 39, 184-199.

Kroll, N. E. A., Rocha, D. A., Yonelinas, A. P., Baynes, K., \& Frederick, C. (2001). Form-specific visual priming in the left and right hemispheres. Brain and Cognition, 47, 564-569.

Kutas, M., \& Federmeier, K. D. (2000). Electrophysiology reveals semantic memory use in language comprehension. Trends in Cognitive Sciences, 4, 463-470.

Kutas, M., \& Hillyard, S. A. (1980). Reading senseless sentences: Brain potentials reflect semantic incongruity. Science, 207, 203-205.

Lehmann, D. (1987). Principles of spatial analysis. In A. S. Gevins \& A. Remond (Eds.), Handbook of electroencephalography and clinical neurophysiology: Vol. 1. Methods of analysis of brain electrical and magnetic signals (pp. 309-354). Amsterdam: Elsevier.

Marsolek, C. J. (1995). Abstract visual-form representations in the left cerebral hemisphere. Journal of Experimental Psychology: Human Perception and Performance, 21, 375-386.

Marsolek, C. J. (1999). Dissociable neural subsystems underlie abstract and specific object recognition. Psychological Science, 10, 111-118.

Marsolek, C. J., Kosslyn, S. M., \& Squire, L. R. (1992). Form-specific visual priming in the right cerebral hemisphere. Journal of Experimental Psychology: Learning, Memory, and Cognition, 18, 492-508.

McCarthy, G., \& Wood, C. C. (1985). Scalp distributions of event-related potentials: An ambiguity associated with analysis of variance models. Electroencephalography and Clinical Neurophysiology, 62, 203-208.

McClelland, J. L. (1979). On the time relations of mental processes: An examination of systems of processes in cascade. Psychological Review, $86,287-330$.

McGlone, J. (1980). Sex differences in human brain asymmetry: A critical survey. The Behavioral and Brain Sciences, 3, 215-263.

McPherson, W. B., \& Holcomb, P. J. (1999). An electrophysiological investigation of semantic priming with pictures of real objects. Psychophysiology, 36, 53-65.

Miller, E. K., \& Desimone, R. (1994). Parallel neuronal mechanisms for short-term memory. Science, 263, 520-522. 
Miller, E. K., Li, L., \& Desimone, R. (1991). A neural mechanism for working and recognition memory in inferior temporal cortex. Science, 254, 1377-1379.

Morton, J. (1969). Interaction of information in word recognition. Psychological Review, 76, 165-178.

Morton, J. (1979). Facilitation in word recognition: Experiments causing change in the logogen model. In P. A. Kolers, M. Wrolstal, \& H. Bouma (Eds.), Processing of visible language (pp. 259-268). New York: Plenum.

Naccache, L., \& Dehaene, S. (2001). The priming method: Imaging unconscious repetition priming reveals an abstract representation of number in the parietal lobes. Cerebral Cortex, 11, 966-974.

Neuner, F., \& Schweinberger, S. R. (2000). Neuropsychological impairments in the recognition of faces, voices, and personal names. Brain and Cognition, 44, 342-366.

Newcombe, F., DeHaan, E. H. F., Ross, J., \& Young, A. W. (1989). Face processing, laterality and contrast sensitivity. Neuropsychologia, 27, 523-538.

Oldfield, R.C. (1971). The assessment and analysis of handedness: The Edinburgh inventory. Neuropsychologia, 9, 97-113.

Paller, K. A., \& Gross, M. (1998). Brain potentials associated with perceptual priming vs explicit remembering during the repetition of visual word-form. Neuropsychologia, 36, 559-571.

Paller, K. A., Kutas, M., \& McIsaac, H. K. (1998). An electrophysiological measure of priming of visual word-form. Consciousness and Cognition, 7, 54-66.

Perrin, F., Pernier, J., Bertrand, O., \& Echallier, J. F. (1989). Spherical splines for scalp potential and current density mapping. Electroencephalography and Clinical Neurophysiology, 72, 184-187.

Pfütze, E.-M., Sommer, W., \& Schweinberger, S. R. (2002). Age-related slowing in face and name recognition: Evidence from event-related brain potentials. Psychology and Aging, 17, 140-160.

Pivik, R. T., Broughton, R. J., Coppola, R., Davidson, R. J., Fox, N., \& Nuwer, M. R. (1993). Guidelines for the recording and quantitative analysis of electroencephalographic activity in research contexts. Psychophysiology, 30, 547-558.

Proverbio, A. M., Lilli, S., Semenza, C., \& Zani, A. (2001). ERP indexes of functional differences in brain activation during proper and common names retrieval. Neuropsychologia, 39, 815-827.

Rugg, M. D. (1987). Dissociation of semantic priming, word and non-word repetition effects by event-related potentials. The Quarterly Journal of Experimental Psychology: Human Experimental Psychology, 39(A), 123-148.

Rugg, M. D., Doyle, M. C., \& Wells, T. (1995). Word and nonword repetition within- and across-modality: An event-related potential study. Journal of Cognitive Neuroscience, 7, 209-227.

Schacter, D. L., Alpert, N. M., Savage, C. R., Rauch, S. L., \& Albert, M. S. (1996). Conscious recollection and the human hippocampal formation: Evidence from positron emission tomography. Proceedings of the $\mathrm{Na}$ tional Academy of Sciences of the United States of America, 93, 321325

Schacter, D. L., \& Buckner, R. L. (1998). Priming and the brain. Neuron, 20, 185-195.

Schacter, D. L., Delaney, S. M., \& Merikle, E. P. (1990). Priming of nonverbal information and the nature of implicit memory. The Psychology of Learning, 26, 83-123.

Scherg, M., \& Berg, P. (2000). BESA 2000 (Version 4.06) [Computer Software]. Munich, Germany: MEGIS.

Schweinberger, S. R. (1995). Personal name recognition and associative priming in patients with unilateral brain damage. Brain and Cognition, 29, 23-35.

Schweinberger, S. R. (1996). How Gorbachev primed Yeltsin: Analyses of associative priming in person recognition by means of reaction times and event-related brain potentials. Journal of Experimental Psychology: Learning, Memory, and Cognition, 22, 1383-1407.

Schweinberger, S. R. (2001). Human brain potential correlates of voice priming and voice recognition. Neuropsychologia, 39, 921-936.

Schweinberger, S. R., \& Burton, A. M. (2003). Covert recognition and the neural substrate for face processing. Cortex, 39, 9-30.

Schweinberger, S. R., Kaufmann, J. M., \& McColl, A. (2002). Famous personal names and the right hemisphere: The link keeps missing. Brain and Language, 82, 95-110.

Schweinberger, S. R., Landgrebe, A., Mohr, B., \& Kaufmann, J. M. (2002). Personal names and the human right hemisphere: An illusory link? Brain and Language, 80, 111-120.

Schweinberger, S. R., Pfütze, E.-M., \& Sommer, W. (1995). Repetition priming and associative priming of face recognition: Evidence from event-related potentials. Journal of Experimental Psychology: Learning, Memory, and Cognition, 21, 722-736.

Schweinberger, S. R., Pickering, E. C., Burton, A. M., \& Kaufmann, J. M. (2002). Human brain potential correlates of repetition priming in face and name recognition. Neuropsychologia, 40, 2057-2073.

Schweinberger, S. R., Pickering, E. C., Jentzsch, I., Burton, A. M., \& Kaufmann, J. M. (2002). Event-related brain potential evidence for a response of inferior temporal cortex to familiar face repetitions. Cognitive Brain Research, 14, 398-409.

Semenza, C., Mondini, S., \& Zettin, M. (1995). The anatomical basis of proper name processing. A critical review. Neurocase, 1, 183-188.

Sergent, J., MacDonald, B., \& Zuck, E. (1994). Structural and functional organization of knowledge about faces and proper names: A positron emission tomography study. In C. Umiltà \& M. Moscovitch (Eds.), Attention \& Performance XV: Conscious and nonconscious information processing (pp. 203-228). Cambridge, MA: MIT Press.

Shah, N. J., Marshall, J. C., Zafiris, O., Schwab, A., Zilles, K., Markowitsch, H. J., et al. (2001). The neural correlates of person familiarity. A functional magnetic resonance imaging study with clinical implications. Brain, 124, 804-815.

Squire, L. R., Ojemann, J. G., Miezin, F. M., Petersen, S. E., Videen, T. O., \& Raichle, M. E. (1992). Activation of the hippocampus in normal humans-A functional anatomical study of memory. Proceedings of the National Academy of Sciences of the United States of America, 89, 1837-1841

Stark, C. E. L., \& McClelland, J. L. (2000). Repetition priming of words, pseudowords, and nonwords. Journal of Experimental Psychology: Learning, Memory, and Cognition, 26, 945-972.

Talairach, J., \& Tournoux, P. (1988). Co-planar stereotaxic atlas of the human brain. Stuttgart, Germany: Thieme.

Tenpenny, P. L. (1995). Abstractionist versus episodic theories of repetition priming and word identification. Psychonomic Bulletin \& Review, 2, $339-363$.

Tranel, D., Damasio, H., \& Damasio, A. R. (1997). On the neurology of naming. In H. Goodglass \& A. Wingfield (Eds.), Anomia: Neuroana tomical and cognitive correlates (pp. 65-90). New York: Academic Press.

Tsivilis, D., Otten, L. J., \& Rugg, M. D. (2001). Context effects on the neural correlates of recognition memory: An electrophysiological study. Neuron, 31, 497-505.

Valentine, T., Brédart, S., Lawson, R., \& Ward, G. (1991). What's in a name? Access to information from people's names. European Journal of Cognitive Psychology, 3, 147-176.

Valentine, T., Hollis, J., \& Moore, V. (1998). On the relationship between reading, listening, and speaking: It's different for people's names. Memory \& Cognition, 26, 740-753.

VanLancker, D., \& Klein, K. (1990). Preserved recognition of familiar personal names in global aphasia. Brain and Language, 39, 511-529. 
VanLancker, D., \& Ohnesorge, C. (2002). Personally familiar proper names are relatively successfully processed in the human right hemisphere, or, the missing link. Brain and Language, 80, 121-129.

Vitkovitch, M., \& Humphreys, G. W. (1991). Perseverant responding in speeded naming of pictures: It's in the links. Journal of Experimental Psychology: Learning, Memory, and Cognition, 17, 664-680.

Wheeldon, L. R., \& Monsell, S. (1992). The locus of repetition priming of spoken word production. The Quarterly Journal of Experimental Psychology: Human Experimental Psychology, 44(A), 723-761.
Young, A. W., Hellawell, D., \& DeHaan, E. H. F. (1988). Cross-domain semantic priming in normal subjects and a prosopagnosic patient. The Quarterly Journal of Experimental Psychology: Human Experimental Psychology, 40(A), 561-580.

Received June 5, 2002

Revision received March 11, 2003

Accepted April 2, 2003

\section{E-Mail Notification of Your Latest Issue Online!}

Would you like to know when the next issue of your favorite APA journal will be available online? This service is now available to you. Sign up at http://watson.apa.org/ notify/and you will be notified by e-mail when issues of interest to you become available! 
Copyright of Journal of Experimental Psychology / Learning, Memory \& Cognition is the property of American Psychological Association and its content may not be copied or emailed to multiple sites or posted to a listserv without the copyright holder's express written permission. However, users may print, download, or email articles for individual use. 